Please do not remove this page

RMIT

UNIVERSITY

\title{
Correlation between nanomechanical and piezoelectric properties of thin films: an experimental and finite element study
}

Nili Ahmadabadi, Hussein; Cheng, Guang; Venkatesh, T; Sriram, Sharath; Bhaskaran, Madhu https://researchrepository.rmit.edu.au/esploro/outputs/9921858505301341/filesAndLinks?institution=61RMIT_INST\&index=null

Nili Ahmadabadi, H., Cheng, G., Venkatesh, T., Sriram, S., \& Bhaskaran, M. (2013). Correlation between nanomechanical and piezoelectric properties of thin films: an experimental and finite element study. Materials Letters, 90, 148-151. https://doi.org/10.1016/j.matlet.2012.09.036

Published Version: https://doi.org/10.1016/j.matlet.2012.09.036

Repository homepage: https://researchrepository.rmit.edu.au (C) 2012 Elsevier B.V. All rights reserved.

Downloaded On 2023/04/26 21:17:19 +1000 
Thank you for downloading this document from the RMIT Research Repository.

The RMIT Research Repository is an open access database showcasing the research outputs of RMIT University researchers.

RMIT Research Repository: http://researchbank.rmit.edu.au/

\section{Citation:}

Nili Ahmadabadi, H, Cheng, G, Venkatesh, T, Sriram, S and Bhaskaran, M 2013, 'Correlation between nanomechanical and piezoelectric properties of thin films: an experimental and finite element study', Materials Letters, vol. 90, pp. 148-151.

See this record in the RMIT Research Repository at: http://researchbank.rmit.edu.au/view/rmit:18457

Version: Accepted Manuscript

Copyright Statement: (c) 2012 Elsevier Ltd. All rights reserved.

Link to Published Version:

http://dx.doi.org/10.1016/j.matlet.2012.09.036 


\section{Correlation between Nano-Mechanical and Piezoelectric}

\section{Properties of Thin Films: An Experimental and Finite Element}

\section{Study}

Hussein Nili, ${ }^{\dagger, \S}$ Guang Cheng, ${ }^{\ddagger}, \S$ T. A. Venkatesh, ${ }^{*}{ }^{\dagger}$ Sharath Sriram, ${ }^{\dagger}$ and Madhu Bhaskaran*,†

${ }^{\dagger}$ Functional Materials and Microsystems Research Group, RMIT University, Melbourne, Victoria 3001, Australia

${ }^{*}$ Department of Materials Science and Engineering, Stony Brook University, Stony Brook, NY 11794, United States

*E-mail: t.venkatesh@stonybrook.edu,madhu.bhaskaran@gmail.com

$\S$ These authors contributed equally.

\section{ABSTRACT}

Piezoelectric materials perform mechanical-to-electrical energy conversion and have unique and enhanced properties, particularly in the thin film form. In this work, the nanomechanical properties of strontium-doped lead zirconate titanate thin films are investigated by nanoindentation. Finite element modeling of the nanoindentation process allows for a comparison of the simulated and experimentally measured load-displacement curves. New insights correlating the nanomechanical and piezoelectric properties of thin films have been obtained which will enable more efficient design of piezoelectric energy harvesting devices.

Keywords: Thin films; Piezoelectric response; Nanoindentation; Elastic modulus; Instrumented indentation method (IIM) 
Piezoelectric materials have been traditionally used in a variety of sensing, actuating, and transduction applications $[1,2]$. Now, they are increasingly studied in energy harvesting applications to harness mechanical energy in the form of pressure transitions and vibrations [3-6]. This has resulted in an impetus to understand the nanomechanical and electromechanical behavior of piezoelectric materials in their bulk, thin film, and nanowire form $[3-6]$.

The adoption of thin film technology for energy harvesting applications is increasingly favored given the ability to incorporate thin film materials on silicon-based devices and flexible electronic platforms [5,6]. These approaches provide opportunities for micro- and nano-patterning to realize complex energy amplification structures $[5,6]$.

Lead zirconate titanate compounds $\left[\mathrm{Pb}\left(\mathrm{Zr}_{\mathrm{x}} \mathrm{Ti}_{1-\mathrm{x}}\right) \mathrm{O}_{3}(\mathrm{PZT})\right]$ are well-known for their exceptional piezoelectric properties $[7,8]$. The addition of strontium $(\mathrm{Sr})$ to $\mathrm{PZT}$ compounds to realize strontium-doped PZT (PSZT) enhances piezoelectric and ferroelectric properties of the compound both in bulk and thin film structures [9-13]. Longitudinal piezoresponse $\left(d_{33}\right)$ values as high as $892 \mathrm{pm} / \mathrm{V}$ on gold-coated silicon [13] and 1,450 pm/V on platinum-coated silicon [14] are reported for the piezoelectric response of $\left(\mathrm{Pb}_{0.92} \mathrm{Sr}_{0.08}\right)\left(\mathrm{Zr}_{0.65} \mathrm{Ti}_{0.35}\right) \mathrm{O}_{3}$ compounds under the converse piezoelectric effect. Nanomechanical properties of PZT and PSZT thin films play an important role in the functionality of the microelectromechanical systems (MEMS) and energy transduction applications that use these films.

Nanoindentation, with controlled forces (as shown in Fig. 1), has been utilized with in situ electrical measurements to study energy generation from piezoelectric thin films at the nanoscale $[5,15,16]$. Such load-displacement and quantified energy generation measurements will be enhanced by a fundamental understanding of the influence of nano-electro-mechanical properties of the materials on the nanoindentation measurements. Furthermore, such thin film systems are influenced by surface roughness, interface, and substrate effects. Development of 
finite element models which can account for materials property variations, and enable correlation with measurements will prove valuable.

This study has two main aspects. First, nanoindentation experiments were performed on thin films of strontium-doped lead zirconate titanate (Sr-doped PZT or PSZT) using a Hysitron Triboindenter [5] and the corresponding load-displacement curves were recorded for a range of forces from $0.1-10.0 \mathrm{mN}$. It should be noted that the conductive indenter tip was electrically grounded during all measurements, and is electrically isolated from the displacement transducer. Second, a finite element model was developed to characterize the influence of the electromechanical properties on the effective nanoindentation response of PSZT thin films.

The PSZT thin films were deposited by RF magnetron sputtering, onto pre-cleaned platinum-coated silicon substrates. The platinum thin film coating on the substrate was $200 \mathrm{~nm}$ thick, with an adhesion layer to silicon of titanium dioxide $\left(\mathrm{TiO}_{2}\right)$. The PSZT thin films were deposited at $350 \mathrm{~nm} / \mathrm{h}$ to attain thicknesses of 700 and $1400 \mathrm{~nm}$. Full details on the sample preparation and deposition processes can be found in our earlier work $[17,18]$. The synthesized films exhibited strong preferential orientation with their $c$-axis normal to the substrate $[14,17]$.

The load-displacement curves obtained for the 700 and $1400 \mathrm{~nm}$ thick PSZT films are shown in Fig. 2, with the maximum applied force indicated. In general, there is a non-linear increase in the indentation load with an increase in the indentation depth for both the piezoelectric thin films. Significant tip displacement at very low loads is also observed for the $1400 \mathrm{~nm}$ film, which is not observed in the case of the $700 \mathrm{~nm}$ film. This is attributed to the higher surface roughness of the thicker films $\left(R_{\mathrm{a}}\right.$ of $\sim 25 \mathrm{~nm}$ for the $1400 \mathrm{~nm}$ films, as against $\sim 11 \mathrm{~nm}$ for the $700 \mathrm{~nm}$ films), which influences the tip-surface interaction during the initial loading phase [19]. 
A major challenge is the ability to model and quantify the interaction between a defined geometry of the nanoindentation tip, the material surface, and the penetration depth. This is overcome by the use of the instrumented indentation method (IIM) [20-23]. The constitutive relationships for a piezoelectric material that exhibits coupling characteristics between its electrical (i.e., dielectric) and mechanical (i.e., elastic) properties are given by:

$$
\begin{aligned}
\sigma_{\mathrm{ij}} & =C_{\mathrm{ijkl}}^{E} \varepsilon_{\mathrm{kl}}-e_{\mathrm{ijk}} E_{\mathrm{k}} \\
D_{\mathrm{i}} & =e_{\mathrm{ikl}} \varepsilon_{\mathrm{kl}}+\kappa_{\mathrm{ij}}^{\varepsilon} E_{\mathrm{j}}
\end{aligned}
$$

where, $\sigma=$ stress tensor, $\varepsilon=$ strain tensor, $E=$ electric field vector, $D=$ electric displacement vector, $C^{E}=$ elasticity tensor with the superscript ' $E$ ' indicating that the elasticity tensor corresponds to measurement of $C$ at constant or zero electric field, $\kappa^{\varepsilon}=$ permittivity tensor with the superscript ' $\varepsilon$ ' indicating that the permittivity tensor corresponds to measurement of $\kappa$ at constant or zero strain, and $e=$ piezoelectric coupling tensor. Equation 1 is the most general representation of the constitutive equation and has 21 elasticity, 18 piezoelectric, and 6 permittivity (or dielectric) constants that are independent material properties. The nanoindentation response of a piezoelectric material is influenced by its elastic, piezoelectric, and dielectric properties.

The instrumented nanoindentation method involves indenting a substrate material with a conical, spherical, or flat indenter and measuring the complete load-displacement (forcedepth) relationship during the loading and the unloading cycle [20-23]. Within the context of piezoelectric materials, depending on the electrical boundary conditions introduced into the indentation set-up, the electric field or voltage generated (open loop) or electric charge or current generated (closed loop) in the indentation process can be determined as a function of indentation depth as well.

The load-displacement characteristics observed in the nanoindentation response of two PSZT thin films were then compared to the results of a finite element model (FEM) of the 
nanoindentation process, the details of which are as follows. Modified two-dimensional axisymmetric models were developed to simulate the indentation response of PSZT thin films with thicknesses of $700 \mathrm{~nm}$ and $1400 \mathrm{~nm}$ (Fig. 1). We only constrain the bottom side of the sample from any vertical displacement and the left side (which is actually the center of the specimen) from any horizontal displacement. The top side and the right side are not constrained mechanically. Our substrate dimensions were chosen to match with experimental specimens. A commercially available software package, ABAQUS, was used for developing the model. For the $700 \mathrm{~nm}$ film, the finite element model had about 23464 nodes comprising of 23315 elements, which included 6337 four-node axisymmetric (CAX4E) elements and 16978 four-node bilinear, reduced integration axisymmetric (CAX4R) elements. For the $1400 \mathrm{~nm}$ film, the model had about 21978 nodes with 21810 elements, which included 11972 CAX4E and 9838 CAX4R elements. The model was designed such that it was large enough to minimize end-effects and the mesh was fine enough in the indented regions for improved accuracy.

The PSZT thin films were considered as exhibiting elastic and dielectric properties that were similar to bulk PZT materials but with different piezoelectric properties (i.e., $d_{33}$ and $\left.d_{31}\right)$. This modification in the piezoelectric properties is due to the fact that PSZT thin films have a piezoresponse coefficient $d_{33}$ of $800-1,000 \mathrm{pm} / \mathrm{V},[5,13,14]$ which is about 2.0-2.5 times greater than that of bulk undoped PZT-5A with $d_{33}$ of $374 \mathrm{pm} / \mathrm{V}[24]\left(d_{31}\right.$ is normally $30-45 \%$ of $d_{33}$ in magnitude, but opposite in sign [3]).

The FEM was used to simulate the nanoindentation of the commercial piezoelectric PZT-5A in bulk and thin films forms, with variation in materials properties to account for doping to enhance $d_{33}$. The electromechanical properties of the piezoelectric materials used in the IIM are presented in Table 1. 
Figure 3 presents the load-displacement data obtained employing the IIM approach for 700 and $1400 \mathrm{~nm}$ thick films utilizing the considerations described above and the parameters listed in Table 1. Firstly, the nanoindentation of bulk PZT-5A is modeled by the IIM approach. The results obtained are typical of experimental results reported for PZT ceramics and thin films, with $\sim 70 \mathrm{~nm}$ penetration at $1 \mathrm{mN}$ load [25-28]. Secondly, the piezoelectric properties of the material were modified to relate to an intermediate $d_{33}$ of $600 \mathrm{pm} / \mathrm{V}$ and then to $1000 \mathrm{pm} / \mathrm{V}$ (as in Table 1). This resulted in a noticeable increase in the stiffness of the load-displacement data (diamond green marker and triangular gold markers in Fig. 3), with a force of $1 \mathrm{mN}$ only having a penetration of $\sim 60 \mathrm{~nm}$ ( $\sim 14 \%$ lesser than bulk PZT-5A). These initial results highlight the influence of piezoresponse coefficients on nanomechanical response of materials.

From Fig. 3, it is evident that the nanoindentation load-displacement response predicted by the finite element model depends strongly on the piezoelectric properties of the substrate material. In general, the indentation responses are observed to be stiffer with increased piezoelectric properties. However, there is little difference in the load-displacement curves obtained from the finite element modeling of nanoindentation of bulk and thin film PSZT. This can be attributed to the fact that the depths of indentation are very small compared to the thickness of the PSZT films.

Overall, there is good agreement between the results of the finite element model and the experimental load-depth response obtained from the nanoindentation experiments on PSZT thin films. In particular, the nanoindentation response of $1400 \mathrm{~nm}$ PSZT thin films are captured very well by the finite element model. This could be attributed to the lack of substrate effects, which become prominent only beyond $10 \%$ of the films thickness $(140 \mathrm{~nm}$ in this case). On the other hand, there is lesser agreement between simulation and measurement for the $700 \mathrm{~nm}$ films. It is expected that further refinements of the finite element 
models to account for surface roughness effects and residual stresses will enhance the observed agreement with experimental results, especially for the thinner films.

In summary, high response piezoelectric thin films of Sr-doped PZT of two thicknesses (700 and $1400 \mathrm{~nm}$ ) were deposited by RF magnetron sputtering. These films were characterized by nanoindentation and observed to exhibit load-displacement slopes that are higher than that observed in standard PZT materials. Finite element models were developed to characterize the nanoindentation response of PSZT and PZT piezoelectric materials in the bulk and thin film form. The modeling results demonstrate that the increased slope of the nanoindentation response curve observed for PSZT originates from its increased piezoelectric coefficient $d_{33}$. This shows that materials with higher piezoresponse are stiffer, which has implications for design of mechanical-electrical energy harvesters. This highlights that nanoindentation can be very useful in correlating the nanomechanical and piezoelectric properties of thin films.

The authors acknowledge support from the Australian Research Council (ARC) through project (DP1092717) and infrastructure (LE110100223) funding. S.S. and M.B. acknowledge ARC Australian Postdoctoral Fellowships from Projects DP110100262 and DP1092717, respectively. The authors also thank Dr. Simon Ruffell for support with the nanoindentation measurements.

[1] S. Tadigadapa, K. Mateti, Meas. Sci. Technol. 20 (2009) 092001.

[2] H.-U. Kim, W.-H. Lee, H.V. Rasika Dias, S. Priya, IEEE Ultrason. Ferroelectr. Freq. Control 56 (2009) 1555-1568. 
[3] T. Rödig, A. Schönecker, G. Gerlach, J. Am. Ceram. Soc. 93 (2010) 901-912.

[4] Y. Qi, N.T. Jafferis, K. Lyons, Jr., C.M. Lee, H. Ahmad, M.C. McAlpine, Nano Lett. 10 (2010) 524-528.

[5] M. Bhaskaran, S. Sriram, S. Ruffell, A. Mitchell, Adv. Funct. Mater. 21 (2011) 22512257.

[6] Z.L. Wang, J. Song, Science 312 (2006) 242-246.

[7] Y. Nemirovsky, A. Nemirovsky, P. Muralt, N. Setter, Sens. Actuators A Phys. 56 (1996) 239-249.

[8] G.H. Haertling, J. Am. Ceram. Soc. 82 (1999) 797-818.

[9] Y. Yu, R.N. Singh, J. Appl. Phys. 88 (2000) 7249-7257.

[10] Y. Yu, J. Tu, R.N. Singh, J. Am. Ceram. Soc. 84 (2001) 333-340.

[11] H. Zheng, I.M. Reaney, W.E. Lee, N. Jones, H. Thomas, J. Am. Ceram. Soc. 85 (2002) $2337-2344$.

[12] S. Sriram, M. Bhaskaran, A.S. Holland, K.T. Short, B.A. Latella, J. Appl. Phys. 101 (2007) 104910

[13] S. Sriram, M. Bhaskaran, A. Mitchell, Scripta Mater. 63 (2010) 189-191.

[14] S. Sriram, M. Bhaskaran, R. Ahluwalia, T.G. Nguyen, N. Ng, D.J. Srolovitz, K. Kalantar-zadeh, A. Mitchell, ACS Nano 5 (2011) 1067-1072.

[15] A. Rar, G.M. Pharr, W.C. Oliver, E. Karapetian, S.V. Kalinin, J. Mater. Res. 21 (2006) $552-556$

[16] H. Nili, K. Kalantar-zadeh, M. Bhaskaran, S. Sriram, Prog. Mater. Sci. (2012), http://dx.doi.org/10.1016/j.pmatsci.2012.08.001

[17] M. Bhaskaran, S. Sriram, D.R.G. Mitchell, K.T. Short, A.S. Holland, Thin Solid Films $516(2008) 8101-8105$. 
[18] S. Sriram, M. Bhaskaran, J. du Plessis, K.T. Short, V.P. Sivan, A.S. Holland, Micron 40 (2009) 104-108.

[19] M.S. Bobji, S.K. Biswas, J. Mater. Res. 13 (1998) 3227-3233.

[20] H. Lan, T.A. Venkatesh, Phil. Mag. 87 (2007) 4671-4729.

[21] H. Lan, T.A. Venkatesh, Acta Mater. 55 (2007) 2025-2041.

[22] T.A. Venkatesh, K.J. Van Vliet, A.E. Giannakopoulos, S. Suresh, Scripta Mater. 42 (2000) 833-839.

[23] G. Cheng, T.A. Venkatesh, Phil. Mag. Lett. 92 (2012) 278-287.

[24] http://www.morganelectroceramics.com/resources/technical-publications/ [File TP226]

[25] T.-H. Fang, S.-R. Jian, D.-S. Chuu, J. Phys.: Cond. Matter 15 (2003) 5253-5259.

[26] P. Delobelle, E. Fribourg-Blanc, O. Guillon, C. Soyer, E. Cattan, D. Rèmiens, Integr. Ferroelectr. 69 (2005) 213-221.

[27] A. Rambabu, K. Sudheendran, K.C. James Raju, Integr. Ferroelectr. 119 (2010) 13-21.

[28] D. Liu, B. Zhou, S.H. Yoon, H.C. Wikle III, Y. Wang, M. Park, B.C. Prorok, D.-J. Kim, Ceram. Int. 37 (2011) 2821-2828.

\section{GRAPHIC ABSTRACT}
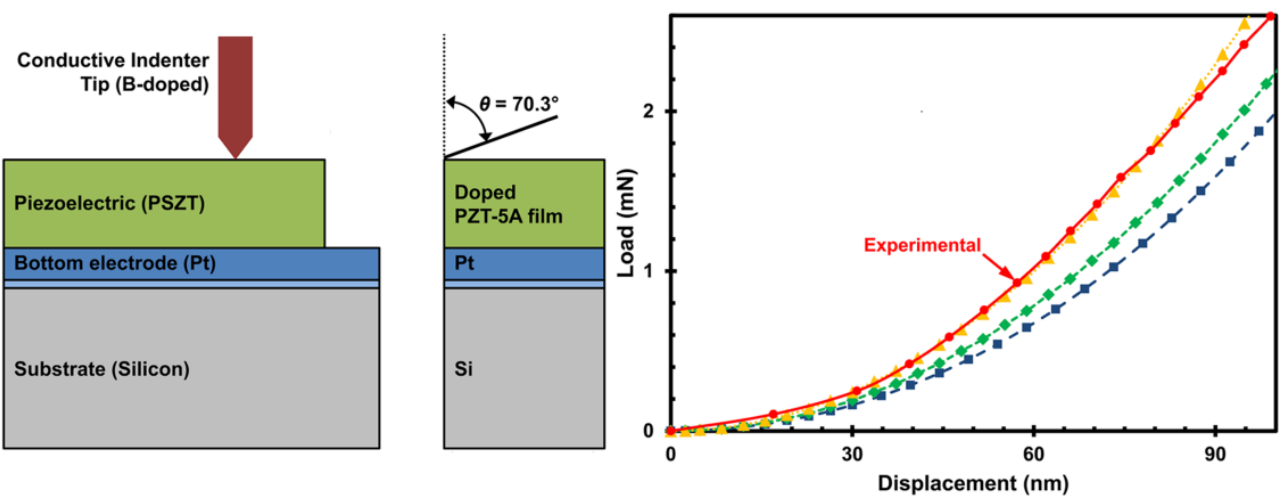
TABLE (WITH CAPTION)

Table 1. The electromechanical properties of PZT-5A invoked to characterize their indentation response.

\begin{tabular}{|c|c|c|c|c|c|c|c|c|c|c|c|}
\hline \multirow{2}{*}{$\begin{array}{c}\text { Materials and } \\
\text { Properties }\end{array}$} & \multicolumn{5}{|c|}{$\begin{array}{c}\text { Elastic } \\
\left(10^{10} \mathrm{~Pa}\right)\end{array}$} & \multicolumn{3}{c|}{$\begin{array}{c}\text { Piezoelectric } \\
(\mathrm{pm} / \mathrm{V})\end{array}$} & \multicolumn{3}{c|}{$\begin{array}{c}\text { Dielectric } \\
\left(10^{-9} \mathrm{C} / \mathrm{Vm}\right)\end{array}$} \\
\cline { 2 - 28 } & $C_{11}^{E}$ & $C_{12}^{E}$ & $C_{13}^{E}$ & $C_{33}^{E}$ & $C_{44}^{E}$ & $C_{66}^{E}$ & $d_{31}$ & $d_{33}$ & $d_{15}$ & $\varepsilon_{11}$ & $\varepsilon_{33}$ \\
\hline $\begin{array}{c}\text { PZT-5A } \\
\left(d_{33}=374 \mathrm{pm} / \mathrm{V}\right)\end{array}$ & 12.1 & 7.59 & 7.54 & 11.1 & 2.11 & 2.26 & -171 & 374 & 583 & 8.11 & 7.35 \\
\hline $\begin{array}{c}\text { PZT-5A } \\
\left(d_{33}=1000 \mathrm{pm} / \mathrm{V}\right)\end{array}$ & 12.1 & 7.59 & 7.54 & 11.1 & 2.11 & 2.26 & -300 & 1000 & 583 & 8.11 & 7.35 \\
\hline
\end{tabular}

\section{FIGURE CAPTIONS}

Figure 1. Schematic illustrating nanoindentation of PSZT thin films: the experimental set-up (left) and finite element modeling (right).

Figure 2. Typical experimental load-displacement curves obtained at various maximum forces from the nanoindentation of PSZT thin films of thicknesses: (a) $700 \mathrm{~nm}$ and (b) $1400 \mathrm{~nm}$.

Figure 3. The load-displacement response obtained from the nanoindentation of PSZT films are compared to the finite element simulations of a standard PZT-5A thin film and PZT-5A thin films with enhanced $d_{33}$ properties. Results are shown for film thickness of (a) $700 \mathrm{~nm}$ and (b) $1400 \mathrm{~nm}$. 